\title{
A pertussis toxin sensitive G-protein-independent pathway is involved in serum amyloid A-induced formyl peptide receptor 2-mediated CCL2 production
}

\author{
Ha Young Lee ${ }^{1,2}$, Sang Doo Kim ${ }^{1,2}$, \\ Jae Woong Shim ${ }^{1,2}$, Hak Jung Kim ${ }^{1,2}$, \\ Jeanho Yun ${ }^{2,3}$, Suk-Hwan Baek ${ }^{4}$, \\ Koanhoi Kim ${ }^{5}$ and Yoe-Sik Bae $e^{1,2,6}$ \\ ${ }^{1}$ Department of Biological Science \\ Sungkyunkwan University \\ Suwon 440-746, Korea \\ ${ }^{2}$ Mitochondria Hub Regulation Center \\ ${ }^{3}$ Department of Biochemistry \\ College of Medicine, Dong-A University \\ Busan 602-714, Korea \\ ${ }^{4}$ Department of Biochemistry and Molecular Biology \\ College of Medicine, Yeungnam University \\ Daegu 705-717, Korea \\ ${ }^{5}$ Department of Pharmacology \\ Pusan National University College of Medicine \\ Yangsan 628-870, Korea \\ ${ }^{6}$ Corresponding author: Tel, 82-31-290-5914; \\ Fax, 82-31-290-7015; E-mail, yoesik@skku.edu \\ DOI 10.3858/emm.2010.42.4.029
}

Accepted 8 February 2010

Available Online 22 February 2010

Abbreviations: FPR2, formyl peptide receptor 2; HUAECs, human umbilical artery endothelial cells; HUVECs, human umbilical vein endothelial cells; PTX, pertussis toxin; SAA, serum amyloid A

\begin{abstract}
Serum amyloid $A(S A A)$ induced CCL2 production via a pertussis toxin (PTX)-insensitive pathway in human umbilical vein endothelial cells (HUVECs). SAA induced the activation of three MAPKs (ERK, p38 MAPK, and JNK), which were completely inhibited by knock-down of formyl peptide receptor 2 (FPR2). Inhibition of p38 MAPK and JNK by their specific inhibitors (SB203580 and SP600125), or inhibition by a dominant negative mutant of p38 MAPK dramatically decreased SAA-induced CCL2 production. Inactivation of $G_{i}$ protein(s) by PTX inhibited the activation of SAA-induced ERK, but not p38 MAPK or JNK. The results indicate that SAA stimulates FPR2-mediated activation of p38 MAPK and JNK, which are independent of a PTX-sensitive G-protein and are essential for
\end{abstract}

SAA-induced CCL2 production.

Keywords: atherosclerosis; chemokine CCL2; endothelial cells; FPR2 protein, human; pertussis toxin; serum amyloid $A$ protein

\section{Introduction}

Serum amyloid A (SAA), a major acute-phase protein, is an important component of responses to infection or injury (Uhlar and Whitehead, 1999). Previous studies have shown that the local concentration of SAA is increased in a pro-inflammatory environment by the actions of several cytokines, such as interleukin- $1 \beta$, resulting in an elevation of about 1000 -fold during acute-phase reactions compared to the normal state (Malle et al., 1993; Uhlar and Whitehead 1999; Urieli-Shoval et al., 2000). Recently, it has been shown that SAA has cytokine-like properties by modulating several cellular responses (Badolato et al., 1994; Jijon et al., 2005; Lee et al., 2006a; Koga et al., 2008). SAA regulates chemotactic migration of some leukocytes, including monocytes and neutrophils (Badolato et al., 1994). SAA also stimulates production of several cytokines from different cell types, including monocytes, epithelial cells, and synovial cells (Jijon et al., 2005; Lee et al., 2006a; Koga et al., 2008). We have recently reported that SAA stimulates CCL2 production by human umbilical vein endothelial cells (HUVECs; Lee et al., 2009).

SAA stimulates formyl peptide receptor 2 (FPR2), which results in $\mathrm{Ca}^{2+}$ mobilization and cell migration (Su et al., 1999; Ye et al., 2009). Several studies have shown that pertussis toxin (PTX)-sensitive G-proteins are involved in FPR2-mediated cellular responses by SAA, including chemotactic migration (Badolato et al., 1995; Su et al., 1999; He et al., 2003).

Despite the role of SAA in atherosclerosis and the role of FPR2 in SAA-induced CCL2 production by endothelial cells, the signaling pathways involved in this process have not been clearly elucidated. In this study we investigated the role of PTX-sensitive G-proteins and the downstream signaling of FPR2 on SAA-induced CCL2 production by HUVECs. 
A

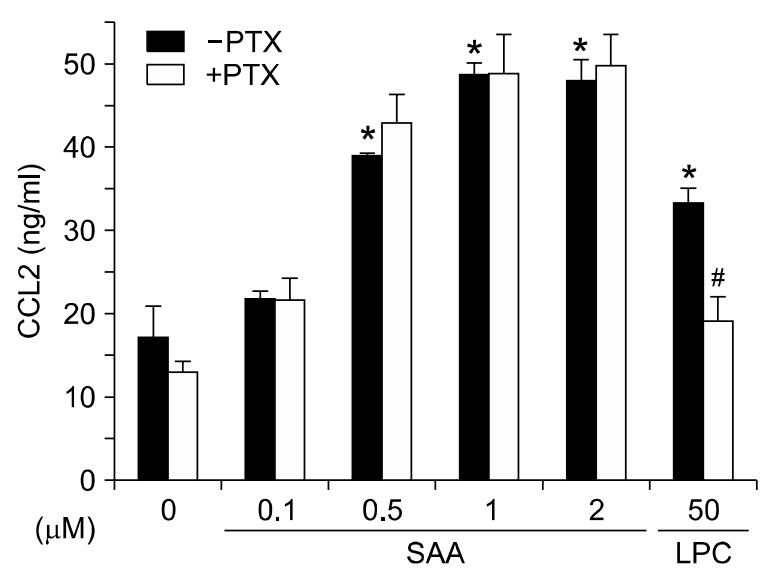

C

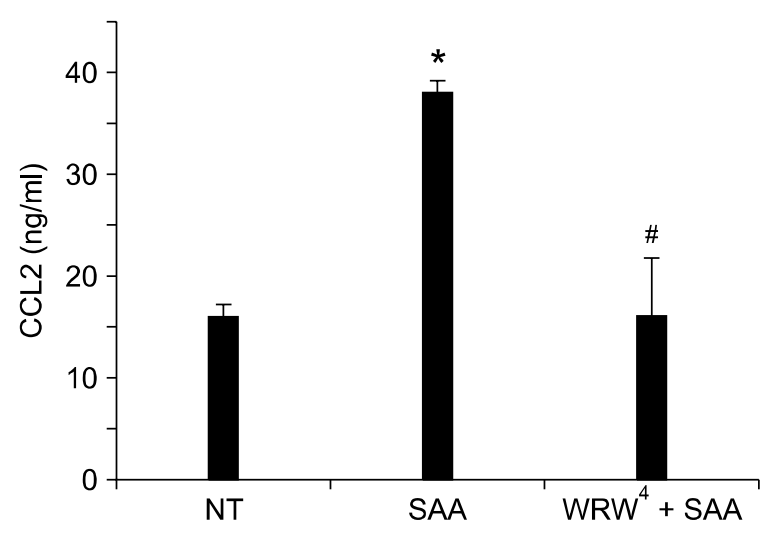

\section{Results}

\section{SAA stimulates CCL2 production in HUVECs by a PTX-independent pathway}

PTX-sensitive G-proteins have been reported to play a role in SAA receptor-mediated $\mathrm{Ca}^{2+}$ signaling (Badolato et al., 1995). We previously demonstrated that stimulation of HUVECs with several concentrations of SAA $(0,0.1,1$, and $2 \mu \mathrm{M})$ for $24 \mathrm{~h}$ induced CCL2 production in a concentration-dependent manner (Lee et al., 2009). To examine the role of PTX-sensitive G-proteins on the SAA-induced CCL2 production by HUVECs, HUVECs were first incubated in the presence or absence of $100 \mathrm{ng} / \mathrm{ml}$ of PTX for $24 \mathrm{~h}$. HUVECs were then stimulated with several different concentrations $(0,0.1,0.5,1$, and $2 \mu \mathrm{M})$ of SAA for an additional $24 \mathrm{~h}$. We found that SAA-induced CCL2 production was not inhibited by pre-incubating the cells with $100 \mathrm{ng} / \mathrm{ml}$ of PTX (Figure 1A). However, lysophosphatidylcholine-induced CCL2 production

\section{B}

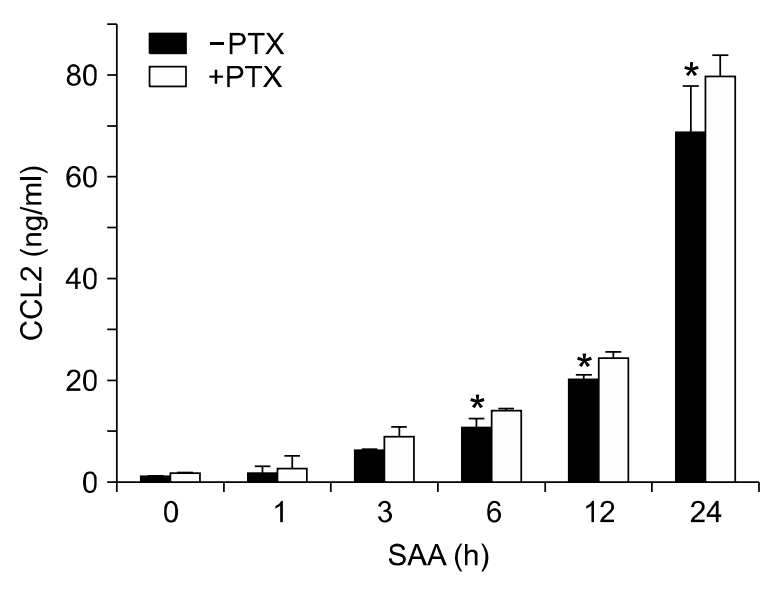

Figure 1. SAA-induced CCL2 production from HUVECs is PTX-insensitive. HUVECs were cultured for $24 \mathrm{~h}$ in the presence or absence of PTX $(100 \mathrm{ng} / \mathrm{ml})$, and then stimulated for $24 \mathrm{~h}$ with different concentrations of SAA $(0,0.1,0.5,1$, and $2 \mu \mathrm{M})$ or $50 \mu \mathrm{M}$ of LPC (A). HUVECs were stimulated for varying times $(0,1,3,6,12$, and $24 \mathrm{~h})$ with $2 \mu \mathrm{M}$ SAA in the absence or presence of PTX (100 $\mathrm{ng} / \mathrm{ml})(B)$. HUVECs were stimulated for $24 \mathrm{~h}$ with $2 \mu \mathrm{M}$ SAA in the absence or presence of WRW ${ }^{4}(10 \mu \mathrm{M})(\mathrm{C})$. The secreted CCL2 levels were determined by ELISA. The results are means \pm SEM of 3 independent experiments performed in duplicate (A-C). ${ }^{*} P<0.05$ compared to the control $(0 \mu \mathrm{M})$. \# Significantly different $(P<0.05)$ from treatment with LPC or SAA alone.

was almost completely inhibited by PTX (Figure 1A). Thus, SAA-induced CCL2 production does not appear to be mediated by a PTX-sensitive G-protein. HUVECs were also stimulated with 2 $\mu \mathrm{M}$ of SAA for several different times $(0,1,3,6$, 12 , and $24 \mathrm{~h}$ ) in the absence or presence of PTX. SAA-stimulated CCL2 production from HUVECs was not inhibited by PTX (Figure 1B). Since SAA has been reported to act on FPR2, we tested the effect of WRW ${ }^{4}$, an FPR2 antagonist, on SAA-induced CCL2 production in HUVECs. Pre-incubation of HUVECs with WRW ${ }^{4}$ prior to SAA addition caused dramatic inhibition of CCL2 production induced by SAA (Figure 1C), indicating that SAA acts on FPR2, resulting in CCL2 production in HUVECs.

\section{SAA induces MAPK activity via PTX-sensitive and -insensitive pathways in HUVECs}

When HUVECs were stimulated for 2-10 min with 2 
A

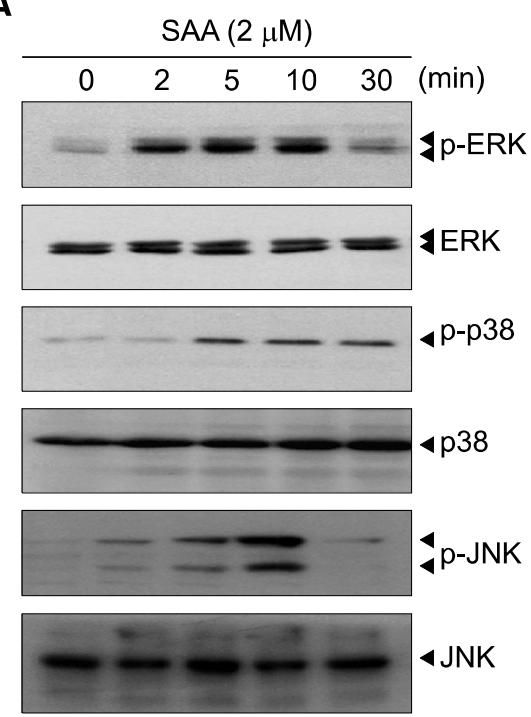

C

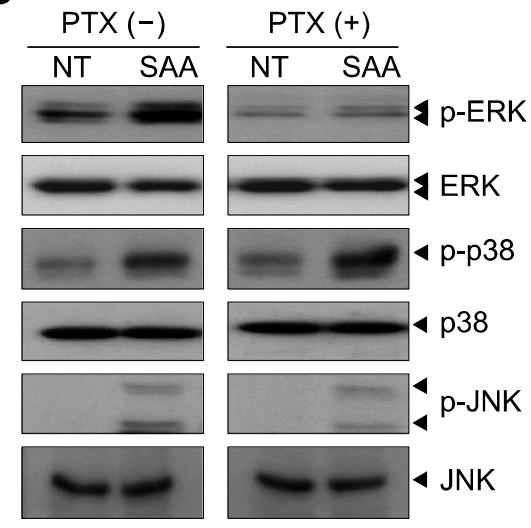

B

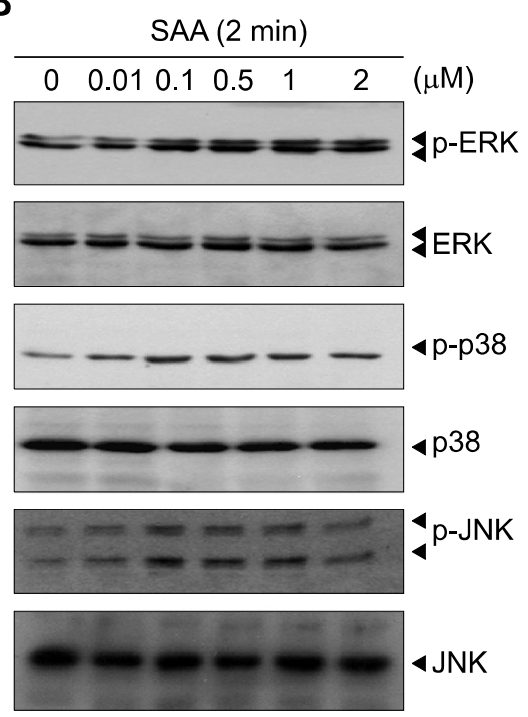

Figure 2. SAA stimulates MAPKs activities in HUVECs. (A) HUVECs were stimulated for different lengths of time $(0,2,5,10$, and $30 \mathrm{~min})$ with $2 \mu \mathrm{M}$ of SAA. (B) HUVECs were stimulated for 5 min with different concentrations of SAA $(0,0.01,0.1,0.5,1$, and $2 \mu \mathrm{M})$. (C) HUVECs were cultured for $24 \mathrm{~h}$ in the presence or absence of PTX $(100 \mathrm{ng} / \mathrm{ml})$, and then stimulated for 5 min with $2 \mu \mathrm{M}$ of SAA or vehicle. (A-C) Phosphorylated ERK, phosphorylated p38 MAPK, or phosphorylated JNK levels were determined by immunoblot analysis using anti-phospho-ERK antibody, anti-phospho-p38 MAPK antibody, or anti-phospho-JNK antibody. The results shown in (A-C) are representative of at least 3 independent experiments.

$\mu \mathrm{M}$ of $\mathrm{SAA}$, the phosphorylation levels of three MAPKs (ERK, p38 MAPK, and JNK) were dramatically increased (Figure 2A). Moreover, when HUVECs were stimulated with different concentrations of SAA, these 3 MAPKs were activated at $100 \mathrm{nM}-2 \mu \mathrm{M}$; (Figure 2B). To examine a role for PTX-sensitive G-proteins on SAA-induced MAPK activation, we pre-treated HUVECs with $100 \mathrm{ng} / \mathrm{ml}$ of PTX prior to SAA stimulation. Figure $2 \mathrm{C}$ shows that PTX completely blocked SAA-induced ERK activity. However, SAA-induced p38 MAPK and JNK activities were not affected by PTX (Figure 2C).

\section{P38 MAPK and JNK regulate SAA-induced CCL2 production}

To determine the roles of individual MAPKs on
SAA-induced CCL2 production, we pre-incubated HUVECs with either PD98059 (a selective MEK inhibitor), SB203580 (a selective p38 MAPK inhibitor), or SP600125 (a selective JNK inhibitor) prior to SAA treatment. We confirmed that all the tested inhibitors specifically inhibited each enzyme (data not shown). SAA-induced CCL2 production was dramatically inhibited by SB203580 and SP600125, but not by PD98059 (Figure 3A), indicating that $\mathrm{p} 38$ MAPK and JNK are essential for SAA-induced CCL2-production. However, MEK-dependent ERK was not involved with SAA-induced CCL2 production. To support the hypothesis that p38 MAPK is essential for the production of CCL2 by HUVECs, we used a recombinant adenovirus expressing the dominant negative mutant of p38 MAPK (AdDNp38). We first confirmed that transfection of AdDNp38 resulted in 
A

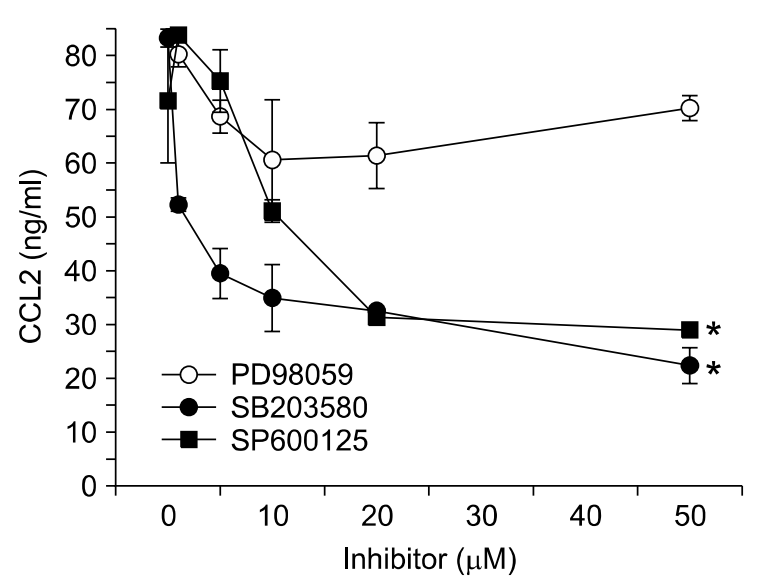

B

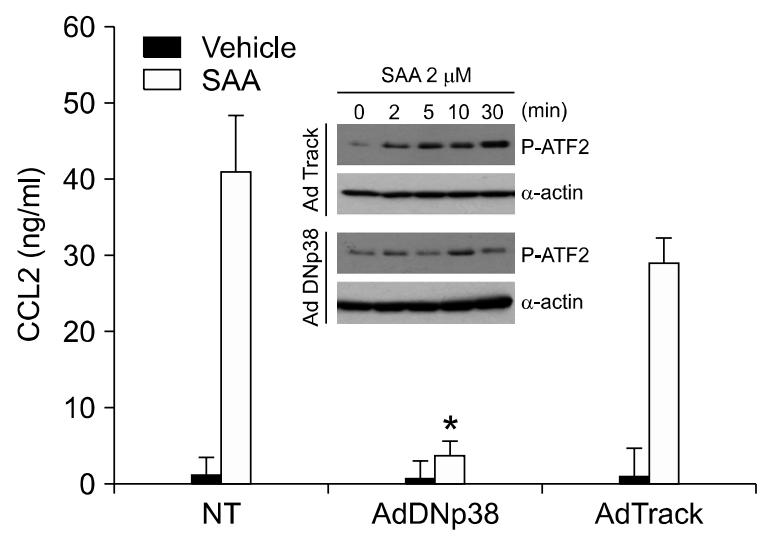

Figure 3. p38 MAPK and JNK are essential for SAA-induced CCL2 production by HUVECs. (A) HUVECs were pre-incubated with several concentrations $(0,1,5,10,20$, or $50 \mu \mathrm{M}$ ) of PD98059 (60 min), SB203580 (15 min), or SP600125 (15 min) prior to stimulation with $2 \mu \mathrm{M}$ of SAA for $24 \mathrm{~h}$. (B) The genes for GFP (AdTrack) or dominant negative p38 (AdDNp38) (MOI; 50) were transferred into HUVECs using recombinant adenoviruses prior to SAA (2 $\mu \mathrm{M}$ ) stimulation for $24 \mathrm{~h}(\mathrm{~B})$ or for 2, 5, 10, or $30 \mathrm{~min}$ (B insert). The amounts of secreted CCL2 were measured by ELISA. Phosphorylated ATF-2 levels were measured by Western blot analysis (B insert). Results are means \pm SEM of 3 independent experiments performed in duplicate $(A, B) .{ }^{*} P<0.05$ compared to the control (SAA only treated).

near-complete inhibition of the phosphorylation of ATF2, which is a well-known p38 MAPK substrate (Figure 3B insert). Further, transfection of AdDNp38 into HUVECs completely inhibited SAA-induced CCL2 production. As a negative control, the transfer of a recombinant adenovirus expressing GFP (AdTrack) did not affect CCL2 production by SAA (Figure 3B). These results strongly suggest that p38 MAPK and JNK are essential for SAA-induced production of CCL2 by HUVECs.

\section{SAA stimulates MAPK activity via FPR2}

The finding that SAA, an FPR2 agonist, induced CCL2 production by a PTX-insensitive pathway in HUVECs led us to examine if FPR2 was involved in SAA-induced MAPK activation in these cells. To verify that SAA-induced MAPK activation was mediated by FPR2 in HUVECs, we used siRNA for FPR2. The down-regulation of FPR2 by siRNA transfection resulted in a near-complete inhibition of SAA-induced ERK phosphorylation (Figure 4). Knock-down of FPR2 using FPR2 siRNA caused inhibition of SAA-induced p38 MAPK and JNK phosphorylation (Figure 4), whereas siRNA for luciferase did not affect SAA-induced MAPK phosphorylation (Figure 4). These results strongly indicate that SAA stimulates MAPK activity via FPR2 in HUVECs.

\section{SAA stimulates CCL2 production in HUAECs via a PTX-independent manner}

Since we observed that SAA stimulates CCL2 production via a PTX-insensitive pathway down-

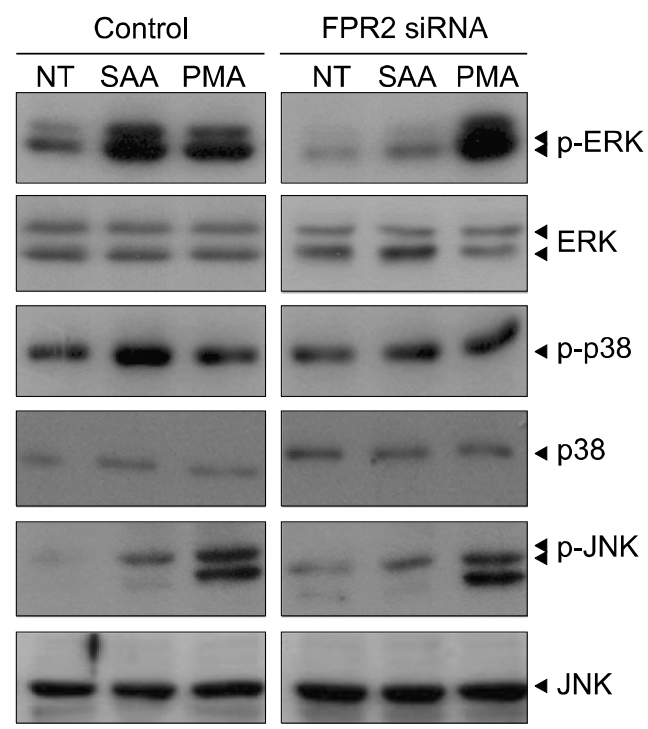

Figure 4. SAA-induced MAPK activity is mediated by FPR2. HUVECs were transfected with $20 \mathrm{nM}$ of FPR2 siRNA or control siRNA for $48 \mathrm{~h}$. The transfected cells were stimulated with vehicle, $2 \mu \mathrm{M}$ of SAA, or 100 nM of PMA for 5 min. Phosphorylated ERK, phosphorylated p38 MAPK, or phosphorylated JNK levels were determined by immunoblot analysis using anti-phospho-ERK antibody, anti-phospho-p38 MAPK antibody or anti-phospho-JNK antibody. The results shown are representative of 3 independent experiments. 

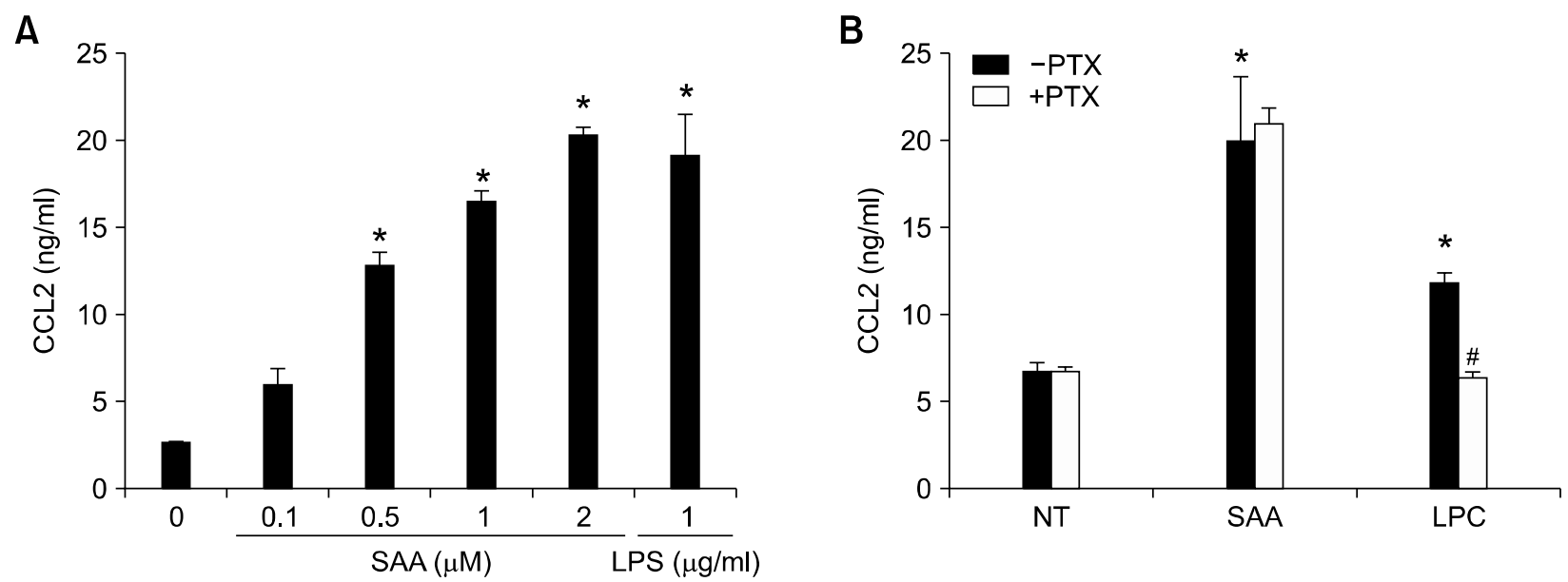

Figure 5. SAA-induced CCL2 production from HUAECs is PTX-insensitive. HUAECs were stimulated for $24 \mathrm{~h}$ with different concentrations of SAA $(0,0.1$ $0.5,1$, and $2 \mu \mathrm{M}$ ) or $1 \mu \mathrm{g} / \mathrm{ml}$ of LPS (A). HUAECs were cultured for $24 \mathrm{~h}$ in the presence or absence of PTX $(100 \mathrm{ng} / \mathrm{ml})$, and then stimulated for $24 \mathrm{~h}$ with $2 \mu \mathrm{M}$ SAA or $50 \mu \mathrm{M}$ LPC (B). The secreted CCL2 levels were determined by ELISA. Results are the means \pm SEM of 3 independent experiments performed in duplicate $(\mathrm{A}, \mathrm{B}) .{ }^{*} P<0.05$ compared to the control $(0 \mu \mathrm{M})$. \# Significantly different $(P<0.05)$ from treatment with $\mathrm{LPC}$ alone.

stream of FPR2 (Figure 1), we investigated whether this event is common in other endothelial cells. We first tested the effect of SAA on the production of CCL2 in HUAECs. As expected, SAA stimulated CCL2 production in a concentration-dependent manner (Figure 5A). The potency of SAA-induced CCL2 production was comparable with CCL2 production by LPS in HUAECs. We then investigated the effect of PTX on SAA-induced CCL2 production in the cells. Pre-incubation of HUAECs with $100 \mathrm{ng} / \mathrm{ml}$ of PTX prior to the addition of SAA did not inhibit SAA-induced CCL2 production. In contrast, lysophosphatidylcholine (LPC)-stimulated CCL2 production resulted in near-complete inhibition by PTX in HUAECs (Figure 5B). The results indicate that SAA stimulates CCL2 production from HUAEC in a PTX-insensitive manner.

\section{Discussion}

Previous studies have shown that many SAA-induced signals are inhibited by PTX, suggesting that PTX-sensitive $G_{i}$-proteins are involved with SAA-induced signaling (Badolato et al., 1995; Lee et al., 2005; Zhao et al., 2007; Björkman et al., 2008). SAA has been reported to stimulate chemotactic migration of some leukocytic cells in a PTX-sensitive manner (Lee et al., 2005; Zhao et al., 2007; Björkman et al., 2008). The increase in intracellular calcium induced by SAA is also mediated by PTX (Badolato et al., 1995). Recently, we also demonstrated that SAA-induced CCL2 expression resulted in near-complete inhibition by PTX in human monocytes (Lee et al., 2008). However, in the present study, we found that SAA-induced CCL2 expression was not affected by PTX (Figure 1). Because many FPR2-mediated signals are known to be mediated by PTX-sensitive G-proteins, these results are very interesting for FPR2-mediated signaling. At this point, it is not clear what causes different signaling in human monocytes and HUVECs. One possible explanation can be derived from the differential cellular context from the two different cell types.

We also examined the intracellular signaling mechanism involved in SAA-induced cytokine production. In the present study, we found that SAA-induced CCL2 production was significantly inhibited by either SB203580, a dominant negative mutant of p38 MAPK or SP600125 (Figures 3A and $3 \mathrm{~B})$. These results indicate that p38 MAPK and JNK, but not ERK, are essential activation components for SAA-induced CCL2 production by human endothelial cells. Pre-incubation of HUVECs with PTX prior to SAA treatment completely inhibits SAA-induced activation of ERK, but not p38 MAPK or JNK (Figure 2C). These results indicate that activation of p38 MAPK and JNK, which are themselves activated by FPR2 in a pathway that is insensitive to PTX, is a prerequisite for the induction of CCL2 by SAA. It also indicates that the activation of ERK activity by SAA, which is mediated by PTX-insensitive signaling, is not necessary for SAA-induced CCL2 production in HUVECs. This is the first report to demonstrate that SAA regulates a cellular response via FPR2 in a 
PTX-independent pathway, and suggests a new mechanism of action for FPR2 in endothelial cells. Since SAA induced CCL2 production, and p38 MAPK and JNK activation are not inhibited by PTX, we can rule out the possible involvement of $G_{i}$ protein in the processes. However, SAA-induced ERK activation was inhibited by PTX. From these results, it may be possible that SAA stimulates p38 MAPK and JNK activation and CCL2 production via other $\mathrm{G}$-protein(s), except $\mathrm{G}_{i}$.

In addition to FPR2, several other targets have been reported as specific receptors for SAA, including receptor for advanced glycation end products (Yan et al., 2000), the HDL receptor, scavenger receptor class B type I (Cai et al., 2005), CLA-1 (CD36 and LIMPII analogous-1), human orthologue of the Scavenger Receptor Class B Type I (Baranova et al., 2005), P2X7 (Christenson et al., 2008), TLR4 (Sandri et al., 2008), and TLR2 (He et al., 2009). Because we found that SAA stimulated CCL2 production via a PTX-insensitive pathway, we confirmed a role for FPR2 in SAA-induced cellular signaling in HUVECs. Transfection of FPR2 siRNA into HUVECs completely inhibited SAA-induced MAPK activities, which are important mediators for the induction of CCL2 by SAA in HUVECs (Figure 4). In a previous report, we also demonstrated that knock-down of FPR2 by siRNA completely blocked SAA-induced CCL2 production by HUVECs (Lee et al., 2009). Taken together, our combined results show that SAA induces CCL2 production via a PTX-insensitive pathway downstream of FPR2 in HUVECs.

In conclusion, we showed that SAA induced CCL2 production via FPR2 in a PTX-insensitive pathway in endothelial cells. This stimulatory effect of SAA was mediated by p38 MAPK and JNK-dependent pathways. We also showed a molecular mechanism for FPR2-mediated signaling that was PTX-independent.

\section{Methods}

\section{Materials}

Recombinant human SAA (endotoxin level $<0.1 \mathrm{ng} / \mu \mathrm{g}$ ) was purchased from Peprotech (Rocky Hill, NJ). PTX, PD98059, SB203580, and SP600125 were from Calbiochem (San Diego, CA). All antibodies for phospho-MAPKs were from Cell Signaling Technology, Inc. (Beverly, MA).

\section{Cell culture}

HUVECs (Cambrex Corporation) and human umbilical artery endothelial cells (HUAECs) were cultured on $0.02 \%$ gelatin-coated (Sigma, St. Louis, MO) $10 \mathrm{~cm}$-dishes in endothelial basal medium supplemented with $10 \%$ FBS and supplements (Cambrex Corporation). Cells between passages 3 and 10 were used for experiments.

\section{Cytokine assay}

Cytokine measurements were performed as previously described (Jo et al., 2004). HUVECs $\left(3 \times 10^{5}\right.$ cells $\left./ 0.3 \mathrm{ml}\right)$ in EGM-2 medium containing 1\% FBS were plated in 24-well plates and kept in a $5 \% \mathrm{CO}_{2}$ incubator at $37^{\circ} \mathrm{C}$. After stimulation, the cell-free supernatants were collected, centrifuged, and assayed for CCL2 by an ELISA (BD Biosciences Pharmingen, San Diego, CA) according to the manufacturer's instructions. To test the role of MAPKs on the SAA-induced CCL2 production, we pre-incubated HUVECs with each MAPK inhibitor (PD98059, SB203580, or SP600125) prior to SAA treatment. For the entire period, the inhibitors were present.

\section{Western blot analysis}

After HUVEC stimulation with SAA, the cells were lysed in lysis buffer (20 mM HEPES [pH 7.2], 10\% glycerol, 150 $\mathrm{mM} \mathrm{NaCl}, 1 \%$ Triton X-100, $50 \mathrm{mM} \mathrm{NaF}, 1 \mathrm{mM} \mathrm{Na}_{3} \mathrm{VO}_{4}, 10$ $\mu \mathrm{g} / \mathrm{ml}$ leupeptin, $10 \mu \mathrm{g} / \mathrm{ml}$ aprotinin, and $1 \mathrm{mM}$ PMSF). Detergent insoluble materials were pelleted by centrifugation $\left(12,000 \times g\right.$ for $15 \mathrm{~min}$ at $\left.4^{\circ} \mathrm{C}\right)$, and the soluble supernatant fraction was removed and stored at either $-80^{\circ} \mathrm{C}$ or used immediately. Proteins were separated in $10 \%$ SDS-polyacrylamide gel and blotted onto a nitrocellulose membrane. Subsequently, the membranes were incubated with specific 1:5000 diluted goat anti-rabbit IgG antibodies, combined with horseradish peroxidase and antigen-antibody complexes were visualized by enhanced chemiluminescence (Cho et al., 2008).

\section{Construction of recombinant adenovirus expressing dominant negative mutant p38 MAPK}

Recombinant adenoviruses were prepared via homologous recombination in $E$. coli using the AdEasy Adenoviral Vector System (Stratagene, La Jolla, CA). The dominant negative p38 mutant from pcDNA3 p38 (TY > AF; kindly provided by Dr. J. Han, The Scripps Research Institute, La Jolla, CA) was cloned into the Shuttle vector, linearized using Pme I and transfected with the pAdEasy-1 vector into E. coli BJ5183. Recombinant adenoviral DNA was then transfected into 293 cells, followed by the generation of replication-deficient recombinant adenoviruses. The adenoviruses harboring genes of interest were isolated using a commercial adenovirus purification kit (Cell Biolabs Inc., San Diego, CA) according to the manufacturer's instructions. The viral titer was determined using a QuickTiter ${ }^{\text {TM }}$ Adenoviral Quantitation Kit (Cell Biolabs Inc.).

\section{Transfection of siRNA for FPR2 transcripts}

The down-regulation of FPR2 by siRNA was performed, as described previously (Lee et al., 2006b). The HUVECs were transfected with a final concentration of $20 \mathrm{nM}$ FPR2 siRNA, or luciferase siRNA as a control, using electroporation with a Microporator (Digitalbiotechnology, South Korea). The cells were washed with serum-free medium, 
followed by incubation with a transfection mixture for $4 \mathrm{~h}$, and the addition of complete endothelial basal medium.

\section{Data analysis}

The results are expressed as the mean \pm SEM for the number of indicated determinations. Statistical comparisons used Student's $t$-test or ANOVA and statistical significance was considered at a $P<0.05$.

\section{Acknowledgements}

This work was supported by the Korea Science and Engineering Foundation(KOSEF) grant funded by the Korea government(MOST) (No. R01-2007-000-11241-0) and National Research Foundation of Korea grant funded by the Korea government (2009 0093198).

\section{References}

Badolato R, Wang JM, Murphy WJ, Lloyd AR, Michiel DF, Bausserman LL, Kelvin DJ, Oppenheim JJ. Serum amyloid $A$ is a chemoattractant: induction of migration, adhesion, and tissue infiltration of monocytes and polymorphonuclear leukocytes. J Exp Med 1994;180: 203-9

Badolato R, Johnston JA, Wang JM, McVicar D, Xu LL, Oppenheim JJ, Kelvin DJ. Serum amyloid A induces calcium mobilization and chemotaxis of human monocytes by activating a pertussis toxin-sensitive signaling pathway. J Immunol 1995;155:4004-10

Baranova IN, Vishnyakova TG, Bocharov AV, Kurlander R, Chen Z, Kimelman ML, Remaley AT, Csako G, Thomas F, Eggerman TL, Patterson AP. Serum amyloid A binding to CLA-1 (CD36 and LIMPII analogous-1) mediates serum amyloid A protein-induced activation of ERK1/2 and p38 mitogen-activated protein kinases. J Biol Chem 2005;280: $8031-40$

Björkman L, Karlsson J, Karlsson A, Rabiet MJ, Boulay F, Fu $\mathrm{H}$, Bylund J, Dahlgren C. Serum amyloid A mediates human neutrophil production of reactive oxygen species through a receptor independent of formyl peptide receptor like-1. J Leukoc Biol 2008;83:245-53

Cai L, de Beer MC, de Beer FC, van der Westhuyzen DR Serum amyloid $A$ is a ligand for scavenger receptor class $B$ type I and inhibits high density lipoprotein binding and selective lipid uptake. J Biol Chem. 2005;280:2954-61

Cho ML, Jung YO, Kim KW, Park MK, Oh HJ, Ju JH, Cho YG, Min JK, Kim SI, Park SH, Kim HY. IL-17 induces the production of IL-16 in rheumatoid arthritis. Exp Mol Med 2008;40:237-45

Christenson K, Björkman L, Tängemo C, Bylund J. Serum amyloid A inhibits apoptosis of human neutrophils via a P2X7-sensitive pathway independent of formyl peptide receptor-like 1. J Leukoc Biol 2008;83:139-48

He R, Sang H, Ye RD. Serum amyloid A induces IL-8 secretion through a $\mathrm{G}$ protein-coupled receptor, FPRL1/ LXA4R. Blood 2003;101:1572-81
He RL, Zhou J, Hanson CZ, Chen J, Cheng N, Ye, RD. Serum amyloid $A$ induces G-CSF expression and neutrophilia via Toll-like receptor 2. Blood 2009;113:429-37

Jijon HB, Madsen KL, Walker JW, Allard B, Jobin C. Serum amyloid $A$ activates NF-kappaB and proinflammatory gene expression in human and murine intestinal epithelial cells. Eur J Immunol 2005;35:718-26

Jo EJ, Lee HY, Lee YN, Kim JI, Kang HK, Park DW, Baek SH, Kwak JY, Bae YS. Group IB secretory phospholipase A2 stimulates $C X C$ chemokine ligand 8 production via ERK and NF-kappa B in human neutrophils. J Immunol 2004;173: 6433-9

Koga T, Torigoshi T, Motokawa S, Miyashita T, Maeda $\mathrm{Y}$, Nakamura M, Komori A, Aiba Y, Uemura T, Yatsuhashi H, Ishibashi H, Eguchi K, Migita K. Serum amyloid A-induced IL-6 production by rheumatoid synoviocytes. FEBS Lett 2008;582:579-85

Lee HY, Kim MK, Park KS, Bae YH, Yun J, Park JI, Kwak JY, Bae YS. Serum amyloid A stimulates matrix-metalloproteinase- 9 upregulation via formyl peptide receptor like-1-mediated signaling in human monocytic cells. Biochem Biophys Res Commun 2005;330:989-98

Lee HY, Kim MK, Park KS, Shin EH, Jo SH, Kim SD, Jo EJ, Lee YN, Lee C, Baek SH, Bae YS. Serum amyloid A induces contrary immune responses via formyl peptide receptor-like 1 in human monocytes. Mol Pharmacol 2006a;70:241-8

Lee HY, Kim SD, Shim JW, Lee SY, Lee H, Cho KH, Yun J, Bae YS. Serum amyloid A induces CCL2 production via formyl peptide receptor-like 1-mediated signaling in human monocytes. J Immunol 2008;181:4332-9

Lee HY, Kim SD, Shim JW, Yun J, Kim K, Bae YS. Activation of formyl peptide receptor like- 1 by serum amyloid $A$ induces CCL2 production in human umbilical vein endothelial cells. Biochem Biophys Res Commun 2009;380:313-7

Lee MS, Yoo SA, Cho CS, Suh PG, Kim WU, Ryu SH. Serum amyloid A binding to formyl peptide receptor-like 1 induces synovial hyperplasia and angiogenesis. J Immunol 2006b; 177:5585-94

Malle E, Steinmetz A, Raynes JG. Serum amyloid A (SAA): an acute phase protein and apolipoprotein. Atherosclerosis 1993;102:131-46

Sandri S, Rodriguez D, Gomes E, Monteiro HP, Russo M, Campa $A$. Is serum amyloid A an endogenous TLR4 agonist? J Leukoc Biol 2008;83:1174-80

Su SB, Gong W, Gao JL, Shen W, Murphy PM, Oppenheim JJ, Wang JM. A seven-transmembrane, G protein-coupled receptor, FPRL1, mediates the chemotactic activity of serum amyloid A for human phagocytic cells. J Exp Med 1999; 189:395-402

Uhlar CM, Whitehead AS. Serum amyloid A, the major vertebrate acute-phase reactant. Eur J Biochem 1999;265: $501-23$

Urieli-Shoval S, Linke RP, Matzner Y. Expression and function of serum amyloid $A$, a major acute-phase protein, in normal and disease states. Curr Opin Hematol 2000;7:64-9

Yan SD, Zhu H, Zhu A, Golabek A, Du H, Roher A, Yu J, Soto 
C, Schmidt AM, Stern D, Kindy, M. Receptor-dependent cell stress and amyloid accumulation in systemic amyloidosis. Nat Med 2000;6:643-51

Ye RD, Boulay F, Wang JM, Dahlgren C, Gerard C, Parmentier M, Serhan CN, Murphy PM. International Union of Basic and Clinical Pharmacology. LXXIII. Nomenclature for the formyl peptide receptor (FPR) family. Pharmacol Rev 2009;61:119-61

Zhao Y, Zhou S, Heng CK. Impact of serum amyloid A on tissue factor and tissue factor pathway inhibitor expression and activity in endothelial cells. Arterioscler Thromb Vasc Biol 2007;27:1645-50 